\title{
MOTIVATIONS AND DISINCENTIVES IN STUDYING THE LANGUAGES OF THE ASIA-PACIFIC REGION IN AOTEAROA NEW ZEALAND
}

\author{
Carolyn Tait, Stephen Epstein, Diego Navarro, Jonathan Newton, \\ \& Aime Black
}

\author{
Victoria University of Wellington
}

\begin{abstract}
This paper takes as its starting point widespread concern over falling enrolments in languages at the secondary and tertiary levels in New Zealand. Despite broad awareness of the importance of the Asia-Pacific region to Aotearoa New Zealand's future and emphasis given to New Zealand's relationships within the region, the study of its languages has lagged. Consequently, this research investigates factors that cause local students to engage (or not) with the region's languages. Beginning with an overview of research on additional language education in New Zealand schools, this paper then goes on to report on new research our team undertook that draws on interviews with secondary and tertiary students and secondary school careers advisors to flesh out our analysis in ways that can inform policy. In this research, we apply Darvin and Norton's (2015) model of investment, a sociocultural approach to language learning motivation, to organise our data and underpin our discussion of factors that appear to foster or impede interest in additional language education in New Zealand. Our work uncovers encouraging signs: successful additional language learning had a positive impact on identity in many students who developed a sense of self-esteem through their study, imagining futures where they were globally mobile and able to communicate with native speakers, drawing on intercultural skills they had developed. These learners also felt that future employers would value their ability to master a subject widely perceived as difficult. More disturbingly, however, our findings corroborate other research that shows that additional languages lack status in New Zealand's predominantly Anglophone society and that the intrinsic value of languages is not often apparent to students, parents and principals, many of whom view additional language education as too difficult. Assessment practices in senior secondary school and prerequisites for further study can also act as disincentives to continuing the study of additional languages. Furthermore, while careers advisors provided advice on subjects that they saw as relevant, they did not necessarily see the ability to use an additional language as a prerequisite for many careers. New Zealand's changing demographics, along with global internationalisation and migration trends, means increasingly that the capacity to communicate in an additional language has to extend beyond the idea that languages are useful for finding work. Ultimately, we argue that the learning of additional languages in New Zealand, particularly those from Asia-
\end{abstract}


Pacific, deserves broad support as a tool in helping nurture more nuanced engagement with Asia-Pacific communities both internationally and domestically.

Keywords: additional language learning, motivation, enrolment, student perspectives

\section{Introduction}

This project takes as a starting point the urgent need to understand more fully - and to address - declining enrolments in languages, particularly at the secondary and tertiary levels in Aotearoa New Zealand (henceforth, New Zealand) classrooms. Despite growing recognition of the cognitive, cultural, and social benefits of learning a subject language (Adesope, Lavin, Thompson, \& Ungerleider, 2010; Johnson, 2013; Newton, Yates, Shearn, \& Nowitzki, 2010; Sanders, 2013; Stewart, 2005), the overall number of language students in New Zealand, with a few exceptions, has fallen, at times precipitously (Badenhorst \& East, 2015; Jones, 2014; McLauchlan, 2007). Indeed, as reported by the Auckland Language Strategy Working Group (2018), the number of secondary students learning languages as a subject at school decreased by $18.5 \%$ between 2007 and 2017. Equally concerning are attrition rates at key transition points, in particular from Year 10 to Year 11 and from 100-level to more advanced language study at tertiary level.

This decline has continued in the face of pronouncements from the government, academics, and national organisations such as the Asia New Zealand Foundation about the need for New Zealand to build its expertise in languages, and specifically the languages of the Asia-Pacific region, in order to succeed as a small trading nation (Asia New Zealand Foundation, 2016; Chen, 2015; Hawke, et al., 2014; Lowe, 2010; Ward \& East, 2016). While New Zealand is not unique among Anglophone countries in facing challenges in subject language education, this project aims to identify issues specific to the local context that contribute to this trend.

As our literature review reveals, gaps exist not only in our knowledge of why students in New Zealand choose particular languages to study, but also, more crucially, the motivations and disincentives that contribute to enrolment patterns. In particular, information is lacking about factors that underpin decisions to study - or to stop studying - languages at key transitional points in students' educational careers, such as the transitions from Year 9 to Year 10 and Year 10 to Year 11, from secondary school to university, and from 100-level introductory language courses at university to 200- and 300-level courses. Our project sought to obtain fresh data on these issues via student perspectives on language learning, with a focus on the languages of AsiaPacific.

This paper begins with a survey of research literature on language education locally, especially work that privileges student and teacher perspectives. The literature review concludes with discussion of recommendations that have been made for language education in New Zealand. Our research aims are introduced together with Darvin and 
Norton's (2015) model of investment, which provides a valuable theoretical lens for the study. We then outline the research design and methodology adopted for collecting and analysing data, before discussing our findings and their implications for New Zealand language education.

\section{Background}

\section{Research on language learning and teaching in Aotearoa New Zealand}

A useful starting point for this review is a survey of research into language teaching and learning in New Zealand between 2006 and 2010 by Ker, Adams, and Skyrme (2013). The authors found that most research during this period was conducted "as part of personal research programmes of individual lecturers and teachers" (p. 231) and was thus often small-scale and not widely disseminated. Ninety per cent of this research was conducted by staff in tertiary institutions, with only around 5\% focused on classrooms. Similarly, Erlam (2010) called for more "research that goes into [school] classrooms to observe and tell us what is really happening in these specific learning contexts" (p. 38). Erlam also found that most New Zealand-based languages research focused on tertiary level English as an additional language, a situation we found unchanged. While many reasons exist for the focus on English and the marginalisation of additional languages, the most salient explanation lies in the prominence of English in New Zealand and internationally. As a global lingua franca, English carries immense economic, sociocultural, and transactional value. As Kramsch (2014) points out, other languages compete unequally with English for prestige, status, and financial support.

Although research on motivations for language learning in New Zealand is modest in size and scope, studies offer insights on such topics as: attitudes toward foreign language learning (Shearn, 2003; East, 2012b); the use of language learning strategies by foreign language learners (White, 2006); "hybrid" language learning across a mixed German class of Year 12 and 13 students (Badenhorst \& East, 2015); foreign language student attrition (Jones, 2012; McLauchlan, 2007); and education policy related to formal language study (May, 2002; Scarino, 2005; Spence, 2004). We focus here on research that investigates attitudes towards language education in New Zealand and students' motivations.

The 2014 Asia New Zealand Foundation's annual survey of New Zealanders' attitudes to Asia and its peoples showed that almost all respondents (93\%) saw value in learning another language; a gap, however, existed between those seen as the most valuable and those most widely taught. Respondents viewed Chinese (64\%) as most valuable, especially in relation to New Zealand's trade links, but it was then only the fifth most studied language in high school (Asia New Zealand Foundation, 2015). It is worth noting that Chinese, supported by the Confucius Institute's Mandarin language assistants, has now become the most taught international language in primary schools and has also grown in secondary schools. Consistent themes that emerge, however, justify detailed discussion of key studies by Shearn (2003) and McLauchlan (2007). 
Shearn (2003) investigated attitudes towards foreign language learning (FLL), in New Zealand schools, that is, languages other than English and Māori. Data included a survey of the attitudes of Year 8 and 9 students over a two-year period and semistructured interviews with parents and teachers which were compared with data from the United Kingdom, the United States, and Australia. Shearn found that although interest served as the primary motivation for studying a foreign language at the secondary level, participants also perceived language study as being too difficult, unnecessary for future employment, and most popular with girls.

These results corroborate findings that suggest parents and schools exert a strong influence over students' attitudes and choice of subjects to study (e.g., Gardner, 1985; Oskamp, I977; Williams \& Burden, 1997). Of note is the influence of parents, who often had limited or no experience of language learning. While parents in Shearn's study recognised growing opportunities for FLL, they "felt unsure about its value for their children" (p. 306). These attitudes left teachers unsurprisingly pessimistic about the views of parents and non-language teaching colleagues. Importantly, however, attitudes towards FLL amongst students and careers advisors were generally positive, although careers advisors privileged the practical decisions made by students when language study could not be directly related to career choice prerequisites. Nonetheless, comparing these positive views with enrolment numbers points to a gap between attitudes and educational choices. While Shearn's participants did not explicitly state that FLL was more suitable for girls, her data showed that girls were much more likely to enrol in, and continue with language learning than boys, a situation that continues. Seventy-five per cent of students enrolled in third year languages at Victoria University of Wellington in 2018 were female.

Shearn's work supports previous New Zealand research findings (e.g., Education Review Office, 1994; Holt, et al., 2001) that secondary students considered interest in languages and other cultures a major reason for language study. Shearn's participants indicated that they continued with FLL because they enjoyed their classes, felt confident in their progress, were interested in deepening their knowledge of the language and its speakers, and valued the skills they were developing.

Despite these positive dispositions towards FLL, however, concerning trends emerged. Notably, institutional factors compromised foreign language enrolments. For example, constraints such as narrow choice among languages to study, the need to take other subjects, limited instruction hours, and a lack of teachers often dissuaded Year 9 students from foreign languages. Shearn also noted a counterproductive belief that foreign languages are suitable only for top students, an issue complicated by gender disparities in FLL. Shearn found that institutional and teacher-propagated attitudes treating language as a subject for the "most intelligent students" were particularly prevalent in all-boys' schools (p. 305), an issue pointing to the role of school administrations in influencing enrolment (cf. Ward \& East, 2016). In summary, Shearn's study showed how positive student attitudes towards learning languages are 
unlikely to increase FLL uptake without parental support or strategies to address structural constraints.

Some of Shearn's findings are corroborated for tertiary level language study by Oshima (2012) and Oshima and Harvey (2017a; 2017b), who investigated why students who studied Japanese in Year 13 did not continue at university. Oshima found that students discontinued because of a lack of timetable space or judgement that language study was incompatible with their major. Other recent New Zealand studies (East \& Tolosa, 2014; Payne, Howard, \& Ogino, 2017; Scheffer-Cosslett \& Kitchen, 2013) have reached similar conclusions about the impact of curricular constraints.

McLauchlan (2007) conducted a three-year (2004-2007) case study into "foreign" language learning motivations at a New Zealand secondary school, exploring why many Year 11 students discontinue language study $(n=765)$. McLauchlan traced one cohort of Year 11 students' enrolment patterns as they proceeded through Year 12 and Year 13. He found that perceived difficulty was a major factor in attrition, with demanding assessment procedures "reinforcing the [real and perceived] difficulty level of [learning a foreign language]" (p. 18). McLauchlan found that "retention rates for L2 [second language] learning students who have completed Year 11 and progressed into Year 12 are poor and are among the lowest retention rates of all subjects" (p. 43). Similarly, despite signs of increased interest in languages of the Asia-Pacific like Chinese, Spanish and Samoan, enrolments began to decrease significantly in more traditional L2s such as French and German.

McLauchlan argued that retention rates for foreign languages reflect priorities New Zealanders attach to other areas of study and beliefs that students, especially lowachieving students, benefit more from those subjects. In his view, a perceived lack of utility among New Zealand employers may have also helped "catalyse the widespread disillusionment" experienced by young New Zealanders who study a foreign language (p. 16) and led to attrition. Support for his claims comes from Erlam and Hellier (2016) who found that only 200 out of 17,000 job advertisements noted an additional language as desirable or essential. Of these, 111 called for Cantonese, Mandarin, or Taiwanese and 32 for te reo Māori; nearly $90 \%$ of these jobs were in the private sector. When East (2012a) asked teachers to comment on the relationship between additional languages and employment in New Zealand, one stated that "parents can't see beyond the fact that little Johnny is not going to actually use Spanish in their job. They're going to be an engineer or whatever" (p. 39). Interestingly, motivation to study Japanese, the most popular subject language at the time of Shearn's (2003) study, appeared largely instrumental, that is, oriented towards job prospects.

Other factors McLauchlan identified as having an impact on retention include, again, the gendered nature of language study, the amount of time allotted to the subject, a potential lack of inspiring teachers, and the presence of heritage learners in classes, especially in Chinese and Japanese. McLauchlan's participants, like Shearn's, frequently cited timetabling constraints as a factor in discontinuing a language. One 
teacher in East's (2012) study lamented, "I have these students, these really, really good students, and they're doing three sciences, maths and English - no room for a language" (p. 39). However, McLauchlan's analysis of scheduling led him to conclude that timetabling constraints were less of a problem than a "prevailing negative climate" for language study. In his view, New Zealand's relative geographic isolation and entrenched monolingualism had created "widespread apathy, even negativity, towards, language learning" (p. 19).

Researchers have continued to investigate motivation in subject language study in New Zealand (e.g., Daly, 2013; Jones, 2012, 2014; Scheffer-Cosslett \& Kitchen, 2013; Tolosa, East, Barbour, \& Owne, 2017; Ward \& East, 2016). Jones (2012, 2014), for example, investigating enrolment rates in high schools. Analysing Ministry of Education (MOE) statistics and New Zealand Qualifications Authority (NZQA) data, including National Certificate of Educational Achievement (NCEA) results, she found that on average, only around 6\% of students continued language study into Year 13. Like Shearn (2003), McLauchlan (2007) and East (2012), Jones concluded that curricular policies "load the dice insurmountably" against sustained foreign language learning (2012, p. 5), noting how the absence of university and NCEA Level 3 requirements for subject languages contributes to their devalued status. Jones further argues that schools discourage enrolments by leaving languages to compete with other subjects without properly advising students about the former's value. Her research also highlights how disproportionate language enrolments in girls' schools and high decile schools reinforce perceptions that language learning is primarily for girls and/or the elite.

Jones (2014) calls for more effective promotion of language education, stressing that subject language education should focus not on "spending time with the language" but on acquisition (p. 2). She also argues that better practice, and increased time allotted to learning, would foster higher levels of competency and help legitimatise language study. By failing to produce proficient students, Jones asserts schools discourage future study, a situation that occurs in other Anglophone nations (cf. Baker, 2001; Cummins, 2001).

Overall, Jones' $(2012,2014)$ research showed that government initiatives to promote subject language learning for Year 7-10 students from 1998 onward had had little impact on Year 13 enrolments, with rates remaining largely steady from 2003 to 2012. At the time of her research, only 20\% of New Zealand secondary schools had sufficient numbers for a viable Year 13 (NCEA Level 3) class in any language. As she asserts, this low figure "would have to be considered a crisis in a nation that while small and isolated needs to think globally precisely because of those characteristics" (Jones, 2012, p. 5). Jones (2014) maintains that continued language study is discouraged by three key factors: their elective status in New Zealand schools; the process of NCEA accreditation; and negative attitudes from society at large including home, government, school, university and workplace. 
Ward and East (2016) have also investigated the impact of individual schools on subject language study and identify four main concerns that mirror Jones' appraisal:

1. Quality and capability of teaching staff;

2. Timetabling and curriculum choices in schools;

3. Lack of status for languages, compounded by entrenched monolingualism;

4. Lack of a languages policy or foreign language requirements in the curriculum.

In their survey of key stakeholders (i.e., curriculum leaders) involved in the implementation and delivery of foreign language programmes, Ward and East found that, in addition to parents, principals play a key role in language uptake. They note that language learning is ultimately demand led and if schools do not offer a language or treat a subject as being of minimal value, enrolments inevitably decline. Specific curricular decisions can thus "diminish" the value ascribed to language learning (p. 45).

Scheffer-Cosslett and Kitchen's (2013) research into the declining number of secondary school students studying German support such claims. Their small-scale study ( $\mathrm{n}-=6$ ), adopted semi-open, individual interviews to explore students' decisions regarding studying German from Years 10 to 12 . The authors found that motivation to take up or continue with the language resulted from a combination of internal factors (e.g., one's ideal self and expectations of contact with target language users) and external factors (e.g., class size and teacher). Two noteworthy findings were that: (1) participants who were born or had lived outside of New Zealand generally exhibited higher motivation in language study; and (2) learners often developed positive attitudes toward a target culture through learning its language. Research by Tolosa et al. (2017) on the efficacy of online learning of Asian languages corroborates this latter point. Their study, which involved interviews, focus groups and surveys with students and teachers, highlighted the crucial intercultural dimensions of language learning, as in the student comment: "I really like learning more about the language and culture, other than my culture" (p. 57). Similarly, East, Tolosa, Biebricher, Howard, and Scott (2018) present data from focus groups carried out with intermediate school students who reported increased motivation, openness and comfort with difference through learning about target language cultures (see also Newton, Milligan, Yates, \& Meyer, 2010; Newton, et al, 2010).

To conclude this review, we consider a 2015 policy document produced by The New Zealand Association of Language Teachers (NZALT) and Asia New Zealand Foundation for the MOE (Asia New Zealand Foundation, 2016). The report examined "key issues and possible solutions to resolving the decline in language learning in our schools" (p. 1) and offered the following suggestions:

1. Engage the community (e.g., promote profiles of successful multilingual New 
Zealanders; encourage a national debate);

2. Develop a language in education strategy (e.g., the New Zealand curriculum needs to withdraw the "working towards offering a language" statement and make language learning a core subject);

3. Review and update New Zealand Curriculum and NCEA requirements (e.g., make languages a learning area as valued as any other);

4. Provide targeted funding for language learning in schools (e.g., language learning is more common in higher decile schools);

5. Build high-quality capacity in language teaching.

These recommendations align with the action points proposed by McLauchlan (2007):

1. Foreign language study needs to be presented as more important, relevant and desirable;

2. Students, parents, and principals require better appreciation of the inherent value of learning a subject language, along with its applications;

3. A paradigm shift is needed to show how foreign language learning helps students develop as adults and complements chosen careers;

4. The perception of difficulty must be addressed to create a climate of success for foreign language students.

The parallels in these recommendations, and their focus on conditions that make language learning appealing for both personal development and future careers, illustrate the need to understand the perceptions of key players in subject choice decisions and set the scene for our research, to which we now turn.

\section{The study \\ Research aims}

Our main purpose has been to illuminate motivations and disincentives for formal language study at secondary and tertiary level in New Zealand from the perspectives of the primary stakeholders, the students themselves. Because much previous research has privileged teacher and parent perspectives, we also interviewed secondary school careers advisors, a group who influence subject choices at entry to university but who are not well represented in research. In soliciting their perspectives, we have aimed to provide a fresh viewpoint. The inclusion of tertiary students has also been rare in New Zealand contexts. We seek, ultimately, to inform language education policy in New Zealand, to provide a reasoned basis for promoting the study of languages in New 
Zealand, and to contribute to international research literature on motivation, language study and language education policy.

\section{Theoretical framework}

In attempting to understand motivations and disincentives for language learning locally, we draw on Darvin and Norton's (2015) model of investment, which offers a sociocultural perspective for understanding language learning motivation and integrates the concepts of identity, capital, and ideology, as illustrated in Figure 1. Darvin and Norton argue for the crucial role of identity in the process of language learning, which involves an individual joining a community of practice of target language speakers. If students do not value that community (Mogi, 2017) or perceive classroom teaching as ineffective (Norton, 2014), they will resist learning. Norton $(2013$, p. 4) defines identity as "the way a person understands his or her relationship to the world, how that relationship is structured across time and space, and how the person understands possibilities for the future". Employing Bourdieu's (1977) concept of social, cultural and economic capital, Darvin and Norton argue that, regardless of motivational dispositions, language learners need an expectation of return to invest in language learning. Ideology enables the multi-layered complexity of social influences to be considered in relation to learners and their willingness to invest in learning (Mogi, 2017). The intersections between identity, capital and ideology reveal sites of synergy and contestation which, in their interplay, shape the degree to which a student is willing, able, and resourced to engage in language learning. Specifically, these intersections bring affordances for language learning at the same time as they expose larger systematic patterns of control and the positioning of the language learner.

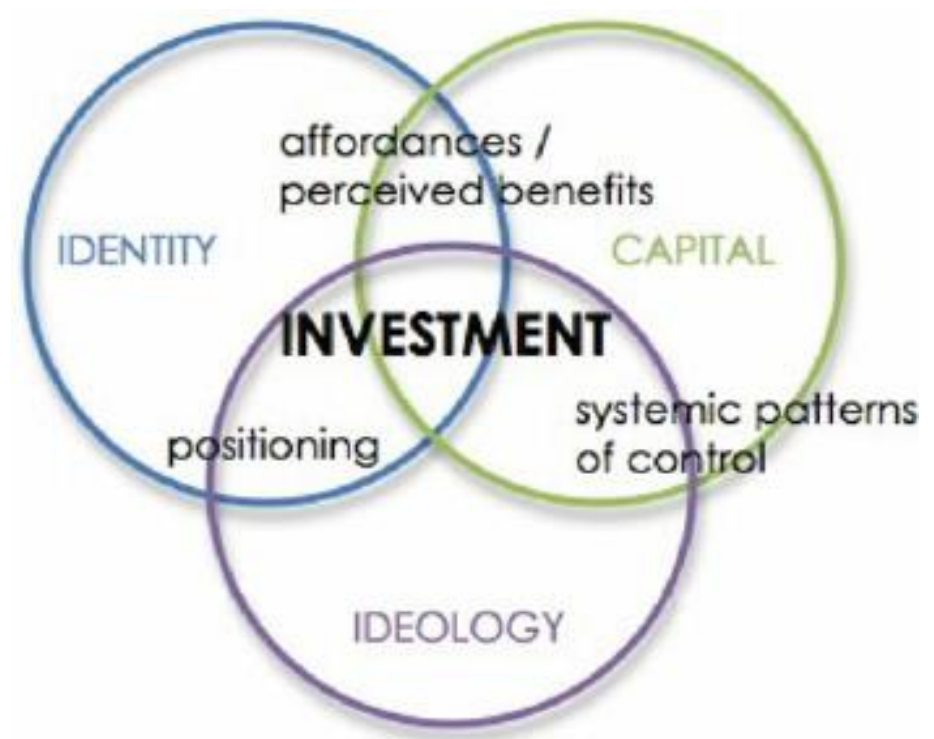

Figure 1. Darvin and Norton's (2015) model of investment (p. 42)

Darvin and Norton's (2015) model has been used to understand language learning in a variety of contexts, ranging from studying English as a Foreign Language (Nasrollahi Shahri, 2018), to the learning of Korean by English teachers in Korea (Gearing \& 
Roger, 2018) and minority languages in schools in multilingual settings (e.g., Lasagabaster, 2017).

Because this model draws on a sociocultural rather than psychological approach, it enables motivations and disincentives reported in our data by students and by school career advisors to be revealed through the concepts of positioning and identity. As an analytic tool, it allows us to extract themes prominent in our participants' testimony and to show how identity, capital and ideology intersect locally; at a more systemic level, the model points to the New Zealand education system and how the wider social and linguistic context moulds students' decisions.

\section{Methodological approach}

In this research, we adopted a qualitative paradigm (Guba \& Lincoln, 1994) through which we sought to describe the diverse perspectives of students and secondary school staff on subject language learning and to tease out factors that motivated or impeded study.

\section{Participants}

Our participants included 27 secondary school students, 13 university students, and 12 high school personnel (nine careers advisors, and three language department staff members). The students were enrolled in several Asia-Pacific languages: Chinese, Samoan, Spanish, and Japanese. The secondary school students were recruited in the Wellington region from four schools, which offered a mix of not only private and public but also boys', girls' and co-ed schools. At the time of data collection in 2017, 19 students were enrolled in a language, but eight had discontinued their study; 19 identified as male and eight as female.

The 13 tertiary-level participants (eight identifying as female, and five as male) were all studying at a New Zealand university. To address our concern with key transition points, we selected five students from 100-level language courses and five from 300level courses. In addition, we recruited three students studying independently through the university's Language Learning Centre.

The 12 high school personnel were recruited from eight secondary schools in Wellington and Christchurch, including the four schools from which student participants were recruited.

\section{Human ethics and participant recruitment}

Prior to seeking participants, we obtained research approval from the Human Ethics Committee at Victoria University of Wellington. Convenience sampling was used to identify secondary schools from which to recruit students. Schools were invited to participate through a letter of introduction sent to the principal, follow-up phone calls 
and face-to-face meetings. Once principals had agreed to allow their school to participate in the study, they were provided with an information sheet and a consent form to sign.

Secondary student participants were recruited through language teachers at their school; those interested were given an information sheet and consent form to sign. University students were invited to participate through information on course websites presented by lecturers. Those interested were likewise provided with information sheets and consent forms. The secondary school staff participants were recruited through professional networks. All students participated in focus group interviews of between two and six. School staff were interviewed individually, either by Zoom ${ }^{\circledR}$, by phone or in person at their school.

\section{Data collection}

Our data, collected between June and September 2017, consist of five secondary school focus group interviews, four university focus group interviews and 12 staff interviews. Focus groups met at the institution where students were enrolled. In secondary schools, interviews took place outside of scheduled class hours, typically at lunch, and a light meal was provided by the interviewer. The interviews were audio-recorded.

\section{Interview protocols}

The focus group interviews were semi-structured according to a set of prompt questions, and the interviewers allowed discussion threads to evolve and lead to followup questions. Focus groups began with a presentation of ground rules (i.e., encouraging all present to participate and valuing others' contributions; not discussing school staff members; and agreeing that discussion would remain confidential to participants). Individual interviews with staff members adopted the same approach. Focus groups typically lasted 50 to 60 minutes, and individual interviews around 30 minutes.

\section{Data analysis}

All interview recordings were transcribed and uploaded to Nvivo® for analysis. In keeping with an interpretivist research paradigm, we conducted a qualitative thematic analysis of the data. This analysis involved initial inductive coding to identify emerging themes which were refined through iterative readings and discussion of the data by research team members. Once this analysis was completed, themes were further categorised using Darvin and Norton's (2015) model of investment, as discussed above.

\section{Findings}

In this section, we present the findings of our thematic analysis with supporting indicative quotes. The themes are not arranged hierarchically, nor, given the study's qualitative nature, are the data interpreted in numerical fashion. We have titled each 
theme with a gerund form (e.g., "developing," "becoming") to capture the dynamic nature of investment and motivation (Charmaz, 2006).

We have categorised the primary themes relating to motivations for language learning that emerged from our data as follows:

- Developing confidence as a language user

- Setting oneself apart

- Becoming a global citizen

- Seeing language learning as an asset

- Experiencing other cultures

- Encountering languages in primary school.

We also identified a set of primary themes related to disincentives for language learning:

- Not enjoying language study

- Needing to put in too much effort

- Seeing language learning as irrelevant

- Encountering systemic constraints

- Learning languages in classrooms.

\section{Motivations for language learning}

Developing confidence as a language user

Some students had opportunities beyond the classroom to build confidence both in their ability to learn the language they were studying academically and to use it in communicative situations:

Just a really fun subject, and I got really good grades in it at school and it was cool seeing how far I had come, because I started off not knowing how to say anything, to being able to have conversations about politics and stuff which was real cool. (Tertiary student)

The mastery experiences developed while learning a language formally may therefore differ markedly from those developed in an immersion situation. As a tertiary student commented: "The opposite is true; when you do something that you should know and you don't know it, it kind of sucks. We felt that while ... when we went over to Japan."

Experience of using a foreign language to communicate also creates affordances for exploring different cultures, and motivation was enhanced when students saw direct practical applications outside the classroom. These practical applications can be a double-edged sword however. For the student above, confidence in an academic setting could also be threatened in interactions with native speakers. This issue highlights the tensions that can arise in transitioning to language use beyond the classroom. 


\section{Setting oneself apart}

For some students, language study can help develop self-esteem; successful language study offers a point of distinction. For example, one secondary student attributed language learning to aptitude: "I think I enjoyed it because I felt like I had a sort of ability to do it well, and I could pick up the nuances of the language where others couldn't really." Another identified his reason for learning simply: "I'm just learning the language for the sake of learning it." He also spoke proudly of how his ability to learn a language allowed him to "show off", even though he was less interested in the future utility of the language. Other secondary students saw language learning as difficult and unlike other subjects: "It's so fundamentally different, it's a bit of a challenge to try unravelling how it works. So, it's a good challenge just mentally; it keeps the brain active."

Comments from students who reported success in language learning corroborated its role in identity formation; they saw themselves acquiring an intellectual skill that other students might regard as different, difficult, or demanding special abilities.

\section{Becoming a global citizen}

For many, travelling abroad or language immersion within New Zealand promoted a global mindset. Students were able to imagine lives in which they interacted with those from other cultures. Careers advisors strongly supported opportunities to travel with families or on school trips as an impetus for language learning. As one said, students who have travelled overseas, "have a much greater investment in taking languages, and continuing with their languages." This sense of investment implies benefits in language study that go beyond school assessment credits. Even students unable to afford overseas travel can cultivate a global orientation through overseas penfriends or hosting international students. The above careers advisor also noted that: "There's nothing better than a real connection. So, that's how they realise they're learning it [language] for a reason."

Some schools recognised the impact of environments that foster a global culture via language learning. When opportunities to use language in study-abroad experiences were discussed, one student recalled the effect of attending a weekend Spanish camp in New Zealand with other schools. "I kind of underestimated how much of an impact that would have had on me learning Spanish" (Secondary student).

Tertiary students often sought opportunities to use their language outside the classroom. Some advanced students reported accessing such environments on their own to interact both with fellow non-native speakers of the language and native-speaking visitors, as for example with Mundo Lingo, a global initiative for social events centred on language exchange. "You can go around and talk to whoever you want, and talk in different languages, and it's really cool to meet people" (Tertiary student). 
According to one careers advisor, global orientations could also be nurtured by interaction with credible models of students who had lived overseas:

...if they can speak to somebody who's gone over there and come back, particularly somebody who's come from their own background - a kid from Upper Hutt who's gone to Japan and lived for two years on Hokkaido, and has come back and has talked about what it was like. (Careers advisor)

One crucial motivation students reported for language study was that it enabled them to envision a future transnational and global self: "I think it [taking a language] really does open up a realistic option of potentially living outside New Zealand" (Secondary student). Conversely, students who had discontinued language study were aware that doing so could have a negative impact on international opportunities: "It just stops I guess career options for when I want to finish university or something; can't go overseas - got to stay in an English-based country" (Secondary student).

In sum, both students and careers advisors regularly saw languages as a resource for accessing opportunities beyond New Zealand. They valued using a language to travel, or even live abroad. In particular, students who continued with a language beyond Year 11 tended to be more aware of opportunities for overseas exchanges. Cognisance of language as a tool for international engagement motivated older students to find ways of using a language beyond the classroom.

\section{Seeing language learning as an asset}

Incentives mentioned by participants were often related to employment:

It kind of teaches you commitment and dedication and several skills which can be applied to almost all jobs, and, in that respect, it's kind of an implicit requirement for lots of jobs even if we aren't told, you must take Language $X$ to be a lawyer. (Secondary student)

Many students felt that employers would value the skills and tenacity required to persist with language learning and treated these qualities as relevant:

When you're applying for a job - if they can see that you can speak another language, it shows a lot about commitment - shows a lot about dedication to a single task and completing it, which obviously employers are looking for in someone. So it shows more than just a language. (Secondary student)

In this area, we observed a distinction between students who continued with language learning and those who did not. When careers advisors indicated that languages were not compulsory or suggested that they might not be useful for a given career option, they created a sense of dissonance with students' expectations, as will be illustrated in discussion of disincentives below. 


\section{Experiencing other cultures}

Students drew a close link between desire to experience other cultures through language and desire to learn that language because the culture associated with it was attractive. One heritage language learner perceived her study as being crucial for accessing her family's cultural background:

So I went to School X and I took Samoan there Year 11 to Year 13, and that's when I got to actually fully grasp the history, the society, the language everything. I thought, oh my gosh, this is pretty awesome, because I never really got that sense of my culture just growing up in New Zealand. (Tertiary student)

Similarly, exposure to cultural elements such as food traditions and popular media promoted language learning: "I like the songs and movies, but more than that I like the culture" (Tertiary student). Another tertiary student spoke of how exposure to Japanese culture at an early age was enhanced by positive personal relationships: “... when I was four or five years old, going to Japanese restaurants lots, the lovely staff members teaching you how to eat with chopsticks properly."

In the early stages of language learning, teaching cultural aspects can provide an incentive to study. As a secondary student recalls, "we had a little Japanese class in primary school, and that kind of interested me in the culture and stuff." Such statements reveal a curiosity about different ways of life that act as an important stimulus to learn a language; conversely, interest in a particular language led to opportunities for engaging more deeply with cultural forms, both the students' own and those of other societies.

\section{Encountering languages in primary school}

Participants who studied a language at secondary and tertiary levels reported that exposure in primary school had a positive impact on their desire to learn languages more generally. For example, an early encounter with Japanese prompted a student to continue at secondary school: "I picked Japanese because my primary school - we kind of studied Japanese as well, and I thought it would be cool to carry it on." The interweaving of early language learning with age-appropriate activities and cultural experiences can promote interest in younger students:

So we actually started in Year 8 . We did like a taster course. I think the main reason I kind of liked it was because our Japanese teacher got us to do cultural stuff, but it was not really cultural stuff; it was like, we're going to learn how to use chopsticks, and as a reward you can try and pick up M\&Ms. I was like, sweet - there's food - I'm loving this. (Tertiary student)

Careers advisors also reported on the influence of exposure to additional languages at home. These included parents who spoke languages other than English and children of 
diplomats who had lived overseas. One careers advisor reported that the school influenced subject choices by using staff to provide exposure to language learning at intermediate school: "So I suppose when you're picking your options maybe they know the teacher and they've got some grounding in the subject, so they're more likely to pick it." This evidence points to how both students' families and opportunities for engaging encounters with language at primary schools can motivate later study.

\section{Disincentives for language learning}

Our student and careers advisor participants also had clear views on factors that turned learners away from language study, as we now discuss.

\section{Not enjoying studying language}

Students expected to enjoy language learning. When asked what would influence a decision to continue study, one secondary student replied: "I think just making it as fun as possible, while still learning as much as you can, because if it's not fun then people do tend to drop out."

Cultural experiences enliven language learning for many students, and some distinguished between language learning in the first two years of secondary school and the final years where skill assessment became more formal:

Last year we didn't really do much of that - a lot of fun things. Even in Year 9 and 10 we used to watch a Japanese movie at least once for the year, but I don't think we really did in Year 11. (Secondary student)

A lack of enjoyment is at times linked to perceptions of a heavy workload and a dearth of cultural learning:

There was a lot of work to do in class, but maybe if they lower the workload and we have more time - we have more of a chance to experience the culture and all the fun stuff, and that would encourage me to keep doing it." (Secondary student)

These statements hint at the balance that teachers need to strike between topics that spark students' interest, curriculum objectives, and assessment goals.

\section{Needing to put in too much effort}

"Effort" recurred as a data theme. Both students and careers advisors commented on languages' high workload. As one secondary student said, "I dislike the workload it has, because you've got to do your other classes as well, and languages require studying outside of school as well, but a lot of it." Students who had dropped a language noted that the subject required more ongoing effort than other subjects. This perception of 
heavy workload was shared by a secondary school careers advisor who also viewed language assessments as being more difficult than other subjects':

Probably the biggest one [i.e., disincentive] was that it [language learning] can be hard and maybe harder than some of their other subjects to get their achievements and credits, so some of them struggle - maybe even an elitism; if you're not going to do the best then you may as well not do it. Also, some of the exams are disproportionally difficult; I think it's an opinion not just of students, but some teachers say that. (Careers advisor)

One careers advisor suggested that, given these perceptions, some students believe that investment in language study did not produce sufficient academic rewards.

\section{Seeing language learning as irrelevant}

Careers advisors also noted students who feel that English's dominance makes other languages irrelevant to their careers place less value on global experiences and knowledge of a second language. As one advisor said, "why would you [students] study a different language if you're going to stay in New Zealand and not go anywhere?" Another remarked that some students discontinue language study because achievement appears to offer little future benefit: "Usually, one of the other reasons though [is] that it doesn't connect with future prospects." Yet another pointed to perceptions of languages' relative lack of value that were often established before secondary school. These expressions about the status of language study by careers advisors can contribute to a low perception of their utility, but, importantly, contrast with the view held by many students themselves, as noted above.

\section{Encountering systemic constraints}

Careers advisors and students both identified larger systemic issues affecting decisions to study a language, such as subject requirements for tertiary entry to specific disciplines. As secondary students develop career goals, they concentrate on relevant subjects: "I've looked at my future. I want to look at engineering or design or something like that, and at the time, and still now, I feel like Chinese is not a part of that - so I dropped it". A careers advisor pointed out that university entrance requirements reinforced this narrowing: "If there are only five options then something's got to give, and generally it will be the language." English literacy requirements also influenced university course prerequisites, and subject languages, strikingly, do not meet the requirements of an "English-rich" course. As one advisor noted, "More and more courses at university require an English-rich subject at Level 3, which is English, geography, art history, history or classical studies." Perhaps paradoxically, the association of subject languages with arts and humanities but not as "English-rich" can prevent them from being seen as part of a vocational pathway or as instrumentally useful. A careers advisor commented: "They have to choose the subjects 
that are required for the particular degree that they're going for, and if they're not going for a BA or languages stream, they don't see that fitting in."

Another systemic issue identified by careers advisors is the organisation of subject languages at secondary school. Even when students were motivated to study a language, the lack of curricular space or timetabling issues could constrain subject combinations. As an advisor emphasised, "The other really big reason to discontinue was subject clashes." Teachers also had a significant impact on students' decisions to study a language. Many secondary schools have a single teacher for a given language, a situation that can either motivate or dissuade, as one advisor noted: "If they have an issue with that teacher, they won't continue with that language. There's just that one teacher that often will teach them the whole of the five years." In sum, the disciplinary requirements of career pathways, timetable structure and teacher constraints influenced subject selection.

\section{Learning languages in classrooms}

Students commented on the pace, process, and content of subject language learning, although reactions differed. Some found language study in Year 11, the first year of formal assessment through the NCEA, more demanding than other subjects:

When it got to Year 11, the work just got a lot more difficult, and just fastcoming but we had to learn much more stuff in much less time. So yeah, it just got a bit over-loading sort of thing.

Conversely, one tertiary student desired a faster pace and attributed her lack of progress to the differing goals of students in her class: "I think it's probably because I'm in a first-year class and most of the people are taking it as an elective" (Tertiary student).

The wide range of needs and purposes, together with varying proficiencies, create significant challenges for teachers to engage all students in a class, both at the secondary and tertiary levels. Some students also reported a mismatch of a class with their expectations:

In Chinese, one of the reasons I signed up is also because on the description it says that it's for people with literally no basic [knowledge]. So I was expecting something that you learn - days, numbers, how to introduce yourself as the first thing - the basic thing to learn a language, but the lessons are not organised that way, and one of the earlier lessons is asking someone to go swimming, which I don't think is really reasonable to use in your daily life. (Tertiary student)

Another student noted that teaching focused on reading and writing rather than speaking, which he had assumed would be the case: 
I think when people lose motivation they don't learn as well, and I feel like that's what lost a lot of the students because they weren't motivated to learn in that sort of - we just struggled with it because we didn't move forward. It was just sort of routine learning like pieces of paper and working off the reading [if] there'd been more vocal activities and getting up and interacting with the class. (Secondary student)

A sense of lack of achievement can result in abandoning a language, as a secondary student experienced: "I dropped it [language] because at the time I'd say I was struggling a little bit in the class." Also, many students found languages required different approaches to other subjects: "It's a challenge. Yeah, I find that it's a real different way of studying than, for example, studying for like biology" (Tertiary student). Such comments suggest that students did not necessarily see how to transfer language learning skills and strategies to other subject areas, which may have had an impact on their perceptions of the relevance of language study. Finally, we note that one student felt no regret for discontinuing because of other study options: "I mean, I could technically pick it up later because it's a language you can learn online" (Secondary student). This last comment suggests an area that deserves greater attention: students may abandon formal language study in favour of independent work, especially as advances in information and communication technology make self-study ever more feasible.

\section{Summary of findings}

Overall, students' comments made it clear that their decisions were influenced by how well teaching and learning matched their expectations and their perception of achievement and opportunities to use the language outside the classroom. Our data also included the views of secondary schools' careers advisors who work with students during the decision-making process. While the views of both groups largely coincided, the themes of Seeing language learning as an asset and Setting yourself apart, though important to students, were strikingly absent in careers advisor discussions. Some students regarded successful language study as part of their identity and expected employers would appreciate this point, even in careers that do not necessitate use of another language. In contrast, careers advisors focused on acquiring a foreign language at school as a utilitarian tool in meeting university and employer demands.

\section{Discussion}

As discussed above, the model of investment developed by Darvin and Norton (2015) provides a lens for understanding how student and careers advisor perceptions affect decisions about language study in the New Zealand context. We now review the themes that emerged in relation to the concepts of identity, capital and ideology from Darvin and Norton's model. These concepts clearly overlap, as is evident in the themes. 


\section{Identity}

Language students form identities in the process of joining a community of language learners and users, as seen in such themes as:

- Developing confidence as a language user

- Setting oneself apart

- Encountering language learning in primary school

- Experiencing other cultures.

Successful language learning had a positive impact on some students' sense of self and allowed them to set themselves apart from peers who had either never begun or had discontinued language study. Many also appreciated that language learning provided opportunities to engage with speakers in target language communities in New Zealand and beyond. They envisioned deeper engagement with these communities, which enhanced their sense of learner identity. Here we see the importance of not only present opportunities, but also an imagined future self in motivating language study, a theme that also emerges in Scheffer-Cosslett and Kitchen's (2013) study of the motivation of high school learners of German (see also East et al., 2018). Positive experiences in primary school equipped students with an understanding of successful language learning and provided incentive to continue. Learning about a target culture likewise offered impetus to persist and encouraged development of a desired cosmopolitan identity, together with intercultural skills (Newton, et al., 2010). Such success contributed to differentiating these learners from others, and their incipient global identity can be regarded as capital in the model used to frame our findings. As Newton, Milligan, Yates, and Meyer (2010, p. 296) argue:

Of all curriculum subjects, the learning of other languages offers perhaps the best opportunities for intensive engagement with cultural diversity and is therefore well placed to foster global-mindedness. Accomplishing this requires commitment to a pedagogy that moves beyond the linguistic and even beyond the communicative, and towards the intercultural in both the content of instruction and in the processes of learning and teaching. It is a reorientation that ties language learning inextricably to education for citizenship (Byram, 2006a, 2006b) and global-mindedness. Openness to diversity, willingness to engage with others and moving away from ethnocentrism in identity construction are all valid and valued outcomes of interculturally informed language teaching and learning, and are highly congruent with the goals of education for globalmindedness.

Influences on local identity were also evident in the data from the student who found that learning Samoan as a subject language revealed a deeper understanding of herself and her connection to her heritage. The rewards of studying community languages and specifically the contribution such study makes to fostering citizenship and identity within multicultural New Zealand thus need further investigation. 


\section{Capital}

Capital is based on the notion of investment with an expectation of return in the future. Themes related positively and negatively to capital include:

- Becoming a global citizen

- Viewing language learning as an asset

- Needing to put in too much effort

- Seeing language learning as irrelevant.

In our analysis Becoming a global citizen functions as a feature of capital because students and advisors often see competence in subject languages as providing tangible benefits. Such competence holds out the prospect of travel and employment, international mobility and opportunities to engage with target language speakers. Furthermore, some students, believing employers would regard successful language acquisition as indicating desired attributes, attached importance to their ability to master a subject perceived as difficult and viewed their invested effort in terms of symbolic capital. In their view, such investment was likely to be recognised and rewarded by others.

However, other students and careers advisors treated the perceived difficulty of language study and the effort demanded as a disincentive. These perceptions reflect the studies of both Shearn (2003) and McLauchlan (2007), who linked notions of languages as "difficult" or "boring" (p. 58) with disincentives to study. Advisors did not necessarily share the view that employers would value the benefits of learning languages, and many comments indicated that they focused on advice for subjects considered relevant to specific careers and saw subject language education as less pertinent in New Zealand.

Hence, some students were drawn towards their affinity with group identity (Gee, 2000) as subject language learners and saw this identity as a form of capital. The social value of this identity is contested by others, including careers advisors, who advise students on how current decisions may position them in the future. We see here how capital is determined by the ideologies of specific groups in society, such as those who see English as sufficient to live and work globally. Nonetheless, these ideologies and the conceptions of capital that flow from them are not fixed but are fluid and sensitive to the flow of social, cultural, political, and economic forces.

\section{Ideology}

Ideology, understood as "a complex, layered space where ideational, behavioural, and institutional aspects interact and sometimes contradict each other," has a significant impact on the study of language, as seen in careers advisors' views (Darvin \& Norton, 2015, p. 43). In this model, ideology encompasses such social systems and structures as national assessment regimes, the curriculum and pedagogy of language teaching, 
and the structures that determine the organisation of classes in secondary schools and universities in New Zealand. Themes in our data that relate to ideology include:

- Not enjoying studying languages

- Learning languages in classrooms

- Encountering systemic constraints

In the New Zealand context, curricular issues are a point of contention. Many students reported being unable to continue a language because of required courses and timetabling constraints. Furthermore, entry requirements for particular university courses of study had an impact on subject choices. Students often noted that language study demands differed significantly to those of other subjects. Dissatisfaction with coverage and pace of the curriculum, a lack of opportunity for oral interaction, styles of teaching that did not meet students' needs, and differing goals among students in a class all had negative motivational effects. NCEA assessment practices are determined by what is considered valuable in the New Zealand education system as well as in society. Assessment practices in languages in senior secondary school seemed to privilege reading and writing over oral language and cultural knowledge. Language teachers thus need to consider such disincentives in their preparation and pedagogical approach.

Threaded through the analysis of our findings is how students learning subject languages is positioned by a society that does not necessarily value the endeavour. This positioning is underscored in our data by how educational institutions create contexts for language learning that motivate or deter learners (Diao \& Liu, 2020). The language learners we interviewed, on the other hand, positioned themselves as successful language learners or needing to make pragmatic decisions to give up subject language learning. This alternative positioning situated their motivations and disincentives for language learning within a sociocultural context beholden to patterns of power and control.

\section{Conclusions}

Our study examined the motivations and disincentives for language learning, and the data we collected reveal the complexity of these topics as reported by students and careers advisors. Our findings also highlight how students negotiate their investment in subject language learning at key educational transition points. A dozen years prior to our study, McLauchlan (2007) concluded his research with a series of action points (p. 12 above) to improve retention of subject languages. These recommendations urged attention to the importance and relevance of subject language learning for students, the appreciation of the intrinsic value of language learning by students, parents and principals; the role of languages in careers and in development of self; and the need to address perceptions of difficulty. Our findings suggest that McLauchlan's recommendations remain just as relevant today. 
Notably, belief in the relevance and intrinsic value of language learning was expressed most strongly in our research by senior secondary school students who had continued their study of languages. Careers advisors, on the other hand, focused on requirements for specific careers, and while they valued the intercultural component of subject language education, no advisor cited intrinsic benefits in language learning. We found little evidence among these influential figures of the "paradigm shift" urged by McLauchlan to show how learning a subject language helps students develop as adults and complements rather than detracts from their chosen careers (p. 19).

Similarly, some senior secondary school and tertiary students do continue to perceive subject language learning as difficult, a perception exacerbated by secondary school assessment demands. Perhaps as a result of such disincentives, anticipation that digital communication would diminish "global isolation" (McLauchlan, 2007, p. 19) has not led to increased language enrolments.

We were encouraged, however, that, despite the persistence of these negative factors, our language student participants, both at secondary and tertiary levels, expressed hope for broader uptake of language learning. Such students can advocate for its value to younger peers and speak credibly to the actual effort it requires and the benefits it offers. They represent a largely untapped resource for promoting language study in New Zealand schools.

We acknowledge that our data come from high decile schools whose students may access international experiences more readily than others. To address this limitation, more research is needed on subject language education in low decile schools and in heritage contexts. We did not collect information on the language profiles of the participants. Given New Zealand's increasing linguistic diversity and the home languages that students bring to class, this gap is a limitation of our study. Despite this limitation, and the relatively small scale of this study, the rich qualitative data obtained and the inclusion of careers advisors enabled us to juxtapose their perspectives with secondary and tertiary students in profitable ways. Much room remains for research that explores such topics such as language learning in primary schools in New Zealand (e.g., Daly, 2013); how languages are taught and learned locally, and the impact of language study experiences on learners' linguistic repertoire, intercultural competence and attitudes towards learning about other languages and cultures. Nonetheless, we hope that our data and findings can help address the dearth of empirical work in New Zealand on the learning and teaching of Asia-Pacific languages.

\section{Acknowledgement}

This project was supported by funding from Victoria University of Wellington's 'Enabling Our Asia-Pacific Nation' Strategic Theme (https://www.victoria.ac.nz/strengths/asia-pacific) 


\section{References}

Adesope, O., Lavin, T., Thompson, T., \& Ungerleider, C. (2010). A systematic review and meta-analysis of the cognitive correlates of bilingualism. Review of Educational Research, 80(2), 207-245.

https://doi.org/10.3102/0034654310368803

Asia New Zealand Foundation. (2015). New Zealanders ' perceptions of Asia and Asian Peoples - 2014 Annual Survey. Retrieved from https://www.asianz.org.nz/assets/Uploads/New-Zealanders-Perceptions-ofAsia-and-Asian-Peoples-2014-annual-Survey.pdf

Asia New Zealand Foundation. (2014). New Zealanders' perceptions of Asia and Asian peoples 2013 annual survey. Asia New Zealand Foundation. Retrieved from https://www.asianz.org.nz/assets/Uploads/Perceptions-of-Asia-and-AsianPeoples-2013-Annual-Survey.pdf

Asia New Zealand Foundation. (2016). Five key recommendations for learning languages to thrive in New Zealand schools. Retrieved from https://www.asianz.org.nz/assets/PDFs/594a8a8896/Five-keyrecommendations-for-learning-languages-to-thrive-in-NZ-schools.pdf

Auckland Languages Strategy Working Group. (2018). Strategy for languages in education in Aotearoa New Zealand 2019-2033. Retrieved from https://ilep.ac.nz/sites/ilep.ac.nz/files/2018-

09/Strategy\%20for\%20languages\%20in\%20educationin\%20Aotearoa\%20NZ. pdf

Badenhorst, G., \& East, M. (2015). Hybrid learning in a multi-level German class: Making the most of the reality of combined classes. The New Zealand Language Teacher, 41, 64-77.

Baker, C. (2001). Foundations of bilingual education and bilingualism (3rd ed.). Bristol: Multilingual Matters.

Bourdieu, P. (1977). The economics of linguistic exchanges. Social Science Information, 16(6), 645-668. dx.doi.org/10.1177/053901847701600601

Charmaz, K. (2006). Constructing grounded theory: A practical guide through qualitative analysis. London: Sage Publications.

Chen, M. (2015). Superdiversity stocktake: Implications for business, government and New Zealand. Superdiversity Centre for Law, Policy and Business. Retrieved from

http://www.chenpalmer.com/wp-content/uploads/Superdiversity_Stocktake.pdf

Cummins, J. (2001). Negotiating identities: Education for empowerment in a diverse society (2nd ed.). Los Angeles: California Association for Bilingual Education.

Daly, N. (2013). Student voice and learning languages education in two New Zealand primary schools. The New Zealand Language Teacher, 39, 15-21.

Darvin, R., \& Norton, B. (2015). Identity and a model of investment in applied linguistics. Annual Review of Applied Linguistics, 35, 36-56. doi.org/10.1017/S0267190514000191

Diao, W., \& Liu, H.-Y. (2020). Starting college, quitting foreign language: The case of learners of Chinese language during secondary-postsecondary transition. 
Journal of Language, Identity \& Education, 1-15. doi.org/10.1080/15348458.2020.1726753

East, M. (2012a). Task-based language teaching from the teachers' perspective: Insights from New Zealand. Philadelphia: John Benjamins.

East, M. (2012b). Working towards a motivational pedagogy for school programmes in additional languages. Curriculum Matters, 8, 128-147. Retrieved from https://go-gale-

com.helicon.vuw.ac.nz/ps/i.do?id=GALE\%7CA316203830\&v=2.1\&u=vuw\&i $\mathrm{t}=\mathrm{r} \& \mathrm{p}=\mathrm{AONE} \& \mathrm{sw}=\mathrm{w}$

East, M., \& Tolosa, C. (2014). The stem revolution: What place for languages other than English? The New Zealand Language Teacher, 40, 65-74.

East, M., Tolosa, C., Biebricher, C., Howard, J., \& Scott, A. (2018). Enhancing the intercultural capability of students of additional languages in New Zealand's intermediate schools. Christchurch: University of Canterbury. Retrieved from http://hdl.handle.net/10092/16056

Education Review Office. (1994). Second language learning: National Evaluation Report, 6. Wellington: Educational Review Office.

Erlam, R. (2010). Understanding context and improving communication: Mediating the worlds of the practitioner and researcher. The TESOLANZ Journal, 18, 3139.

Erlam, R., \& Hellier, M. P. (2016). Employer demand for speakers of languages other than English. The New Zealand Language Teacher, 42, 21-30.

Gardner, R. (1985). Social psychology and second language learning: The role of attitudes and motivation. London: Edward Arnold.

Gearing, N., \& Roger, P. (2018). 'I'm never going to be part of it': Identity, investment and learning Korean. Journal of Multilingual and Multicultural Development, 39(2) 155-168. doi/full/10.1080/01434632.2017.1323909

Gee, J. P. (2000). Chapter 3: Identity as an analytic lens for research in education. Review of Research in Education, 25(1), 99-125. doi.org/10.2307/1167322

Guba, E. G., \& Lincoln, Y. S. (1994). Competing paradigms in qualitative research. In N. K. Denzin \& Y. S. Lincoln (Eds.), Handbook of qualitative research (Vol. 2, pp. 105-117). Thousand Oaks, CA: Sage.

Hawke, G., Bedford, R., Kukutai, T., McKinnon, M., Olssen, E., \& Spoonley, P. (2014). Our futures: Te Pae Tawhiti. The 2013 census and New Zealand's changing population. The Royal Society of New Zealand. Retrieved from http://aut.researchgateway.ac.nz/handle/10292/7895

Holt, R., Maeda, H., Sasai, Y., Shaw, C., Waller, Y., \& Young, S. (2001). Year 10 Japanese: A study of retention factors in New Zealand secondary schools. Christchurch: School of Languages, Christchurch Polytechnic Institute of Technology.

https://www.asianz.org.nz/our-resources/reports/new-zealanders-perceptionsof-asia-and-asian-peoples-2014-annual-survey/

Johnson, K. (2013). An introduction to foreign language learning and teaching. London: Routledge. 
Jones, C. (2012). International language learning among final year high school students in New Zealand (Master's Thesis). Victoria University of Wellington, New Zealand.

Jones, C. (2014). The shortage of students studying languages for NCEA Level 3. Set, 2, 24-32. Retrieved from

https://www.nzcer.org.nz/system/files/set2014_2_024.pdf

Ker, A., Adams, R., \& Skyrme, G. (2013). Research in applied linguistics and language teaching and learning in New Zealand (2006-2010). Language Teaching, 46(02), 225-255. doi.org/10.1017/S0261444812000535

Kramsch, C. (2014). Teaching foreign languages in an era of globalization: Introduction. The Modern Language Journal, 98(1), 296-311. doi.org/10.2307/1167322

Lasagabaster, D. (2017). Language learning motivation and language attitudes in multilingual Spain from an international perspective. The Modern Language Journal, 101(3), 583-596. doi.org/10.1017/S0261444812000535

Lowe, D. (2010). The Colombo Plan and 'soft' regionalism in the Asia-Pacific: Australian and New Zealand cultural diplomacy in the 1950s and 1960s.

Retrieved from

http://dro.deakin.edu.au/eserv/DU:30051862/lowe-colomboplan-2010.pdf

May, S. (2002). Where to from here: Charting a way forward for language and education policy in Aotearoa/New Zealand. The TESOLANZ Journal, 10, 22-35.

McLauchlan, A. (2007). The negative L2 climate: Understanding attrition among second language students. Sasakawa Fellowship Fund for Japanese Language Education. Retrieved from

http://www.massey.ac.nz/massey/fms/Prospective\%20Students/scholarships/sa sakawa/documents/L2\%20Research\%20(1).pdf?97AE1029C6DDBACA8E569 026B0E87E6D

Ministry of Social Development (MSD) (2008). Diverse communities: Exploring the migrant and refugee experience in New Zealand. Strategic social policy group. Retrieved from https://www.msd.govt.nz/about-msd-and-our-work/publicationsresources/research/diverse-communities-migrant-experience/index.html

Mogi, Y. (2017). "It's a pity that they have to choose between French and English": Language ideologies at a Japanese overseas school in Belgium. Bellaterra Journal of Teaching \& Learning Language \& Literature, 10(2), 59-76. doi:10.5565/rev/jtl3.735

Nasrollahi Shahri, M. N. (2018). Constructing a voice in English as a foreign language: Identity and engagement. TESOL Quarterly, 52(1), 85-109.

Newton, J., Milligan, A., Yates, E., \& Meyer, L. (2010). Global-mindedness and intercultural competence: Two responses to the challenge of educating for a linguistically and culturally diverse world. In V. Green \& S. Cherrington (Eds.), Delving into diversity: An international exploration of issues of diversity in education (pp. 287-299). Hauppauge, NY: Nova Science. 
Newton, J., Yates, E., Shearn, S., \& Nowitzki, W. (2010). Intercultural communicative language teaching: Implications for effective teaching and learning. Report to the Ministry of Education.

http://www.educationcounts.govt.nz/publications/curriculum/76637/introductio $\mathrm{n}$

Norton, B. (2014). Identity and poststructuralist theory. In S. Mercer. \& M. Williams (Eds.), Multiple perspectives on the self in SLA (pp. 59-74). Bristol: Multilingual Matters.

Oshima, R. (2012). An investigation into the reasons of discontinuance of Japanese amongst first year tertiary students who have studied Japanese to Year 13 at secondary school (Master's thesis). Auckland University of Technology, Auckland, New Zealand. Retrieved from

http://aut.researchgateway.ac.nz/bitstream/handle/10292/4501/OshimaR.pdf?se quence $=3 \&$ isAllowed $=\mathrm{y}$

Oshima, R., \& Harvey, S. (2017a). The concept of learning Japanese: Explaining why successful students of Japanese discontinue Japanese studies at the transition to tertiary education. The Language Learning Journal, 45(2), 153-170.

Oshima, R., \& Harvey, S. (2017b). 'Japanese and the major are incompatible': Institutional reasons for dropping Japanese at the transition from secondary to tertiary education. The Language Learning Journal, 45(4), 499-517. doi.org/10.1080/09571736.2014.963643

Oskamp, S. (1977). Attitudes and opinions. New Jersey: Prentice-Hall.

Payne, R., Howard, J., \& Ogino, M. (2017). An exploration of the role of anime and manga as stimuli for secondary students studying Japanese. The New Zealand Language Teacher. 43, 24-40.

Sanders, R. H. (2013). Why learn a foreign language? Computer, 46(4), 83-85. http://doi.ieeecomputersociety.org/10.1109/MC.2013.148

Scarino, A. (2005). Learning languages in the New Zealand curriculum. Paper commissioned by the New Zealand Ministry of Education for the New Zealand Curriculum Marautanga Project.

Scheffer-Cosslett, P., \& Kitchen, M. (2013). A case study of the motivation of students learning German in a high school. The New Zealand Language Teacher. 39, 2231.

Shearn, S. (2003). Attitudes to foreign language learning in New Zealand schools (PhD Thesis). Victoria University of Wellington, New Zealand.

Spence, G. P. (2004). The practice of policy in New Zealand. Current Issues in Language Planning 5(4), 389-406. doi.org/10.1080/14664200408668265

Spoonley, P., \& Bedford, R. (2012). Welcome to our world? Immigration and the reshaping of New Zealand. Wellington: Dunmore.

Stewart, J. H. (2005). Foreign language study in elementary schools: Benefits and implications for achievement in reading and math. Early Childhood Education Journal, 33(1), 11-16. doi.org/10.1007/s10643-005-0015-5

Tolosa, C., East, M., Barbour, M., \& Owne, H. (2017). Cool or not cool? Learning an Asian language online in the context of communities of online learning. The New Zealand Language Teacher, 43, 51-62. 
Ward, D., \& East, M. (2016). Is language learning languishing? Stakeholders' perspectives on the provision of secondary school foreign language programmes in New Zealand. The Language Teacher, 42, 44 -62.

White, C. (2006). Distance learning of foreign languages. Language Teaching, 39(4), 247-264. https://doi.org/10.1017/S0261444806003727

Williams, M., \& Burden, R. (1997). Psychology for language teachers. Cambridge: Cambridge University Press. 